

\title{
Allergic Skin Reactions to Baclofen Pump: A Case Report
}

\author{
Abubakar MK, Mamuda AA
}

Orthopaedic Unit, Department of Surgery, Bayero University/Aminu Kano Teaching Hospital, Kano, Nigeria

\author{
*Correspondence: Dr MK Abubakar, Orthopaedic Unit, Department of Surgery, Bayero University /Aminu Kano \\ Teaching Hospital, P.M.B 3452, Kano, Nigeria. E-mail: emkeabubakar@mail.com; \\ ORCID - https://orcid.org/0000-0002-3892-6357.
}

\begin{abstract}
Summary
US was a 37-year old man who presented with generalized skin rashes of two years duration. He had a history of cervicothoracic (C6/T1) spine injury seven years earlier and for which he was managed conservatively at a secondary level hospital. He had Baclofen Pump inserted intrathecally in India four years following the spinal injury resulting in persistent spastic paralysis of both lower limbs. He was scheduled for intermittent Baclofen refill at India. Three months after the second drug refill, he developed generalized skin rashes. His vital signs were stable on presentation. He had wide-spread skin rashes.

There was a bulge on the anterior abdominal wall on the right hypochondrial region due to the presence of the metallic implant. The dermatological review suggested foreign body reaction to exclude Acquired Ichthyosis was made. The patient had an explantation done and thereafter, showed remarkable improvement three months after the removal of the Intrathecal Baclofen Pump with healing and disappearance of the skin rash.
\end{abstract}

Keywords: Allergic reaction, Baclofen Pump, Foreign Body Reaction, Skin rash, Spastic paralysis, Spinal injury.

\section{Introduction}

Baclofen was first introduced in 1972, as an antiepileptic drug. However, its efficacy as an antiepileptic agent was poor. However, it was noticed to be efficacious in reducing spasticity, thus it was used for that. ${ }^{[1]} \mathrm{A}$ high dose of the drug is required to achieve a therapeutic effect. Unfortunately, this high dose is associated with side effects. ${ }^{[1,2]}$ The need for high doses and the resultant side effects were drastically reduced with the introduction of Intrathecal Baclofen (ITB) in 1984. [2,-4] Baclofen is a GammaAminobutyric Acid (GABA) agonist that inhibits the monosynaptic and polysynaptic reflexes at the spinal and supraspinal levels, thereby reducing muscle tone. ${ }^{[2,5]}$ The baclofen pump is surgically implanted on the anterior abdominal wall. It delivers a programmed dose of Baclofen via a catheter that is channelled to the epidural space. ${ }^{[1,6,7]}$ ITB controls severe spasticity and dystonia following spinal lesions and intracranial pathology. [1,6,8] The net effect of this manoeuvre is to decrease muscle tone and pain. ${ }^{[8]}$ This will improve the general wellbeing of the patient.

Clinicians must recognize skin reactions that may follow the insertion of a baclofen pump. Though not common, it can significantly affect the patient's well-being. [9] These skin reactions could 
also be secondarily infected and thus serves as a focus for severe infection. This report of a 37-year old man who presented with dermatitis after several months of insertion of baclofen pump highlights the fact that while baclofen pump offers a good option in the control of persistent muscle spasm following SCI, it may be associated with a high risk of allergic skin reactions and infections among other complications.

\section{Case Description}

US was a 37-year old spinal injured male patient who presented to the Surgical Out-Patient Clinic of Aminu Kano Teaching Hospital, Kano, Nigeria with generalized skin rashes of two years duration. The rashes were more on the anterior abdominal wall, back, and over the four limbs. There were associated pruritus and occasional discharge from the rashes on the limbs and anterior abdominal wall. He had a history of spinal injury involving the cervicothoracic region (C6/T1) following a motor vehicular accident seven years earlier. The spinal injury was managed non-operatively at another health facility. He had been paraplegic since the time of the injury.

Four years following the injury (2016), he was referred to a health facility in India on account of persistent spasticity of both lower limbs where he had Intrathecal Baclofen Pump (IBP) insertion. There was a remarkable improvement in the spasticity. He was scheduled for a drug refill procedure after six months. Unfortunately, he could not go back to India until a year later (2017), due to financial constraints. He had drug refill and was also rescheduled for another drug refill procedure six months after. His visit to India was delayed for another year (2018). Three months after his return from the second visit to India for drug refill, he noticed skin rashes that were initially on the anterior abdominal wall around the site of the pump insertion. It subsequently spread to involve the upper back, lower limbs and the upper limbs.

There was occasional. Fever and sero-purulent discharges from the rashes on the lower limbs and the anterior abdominal wall. He got some relieve of these symptoms whenever he took antibiotics (Amoxycillin/Clavulanate) prescribed by the physician in his locality. Six months following the appearance of the rashes he had a prescription of oral steroids (Prednisone) from another physician. Two weeks following the commencement of steroid, the rashes disappeared almost completely but they reappeared about two weeks after stopping steroid therapy. The rashes again remitted following another course of oral steroid only to reappear some weeks later. At that point, he was advised to remove the IBP.

On examination, he was cheerful, not pale, afebrile, anicteric with an axillary temperature of $37.2^{\circ} \mathrm{C}$. The respiratory rate was 20 cycles per minute while the pulse rate and blood pressure were 76 beats per minute and 110/70 $\mathrm{mmHg}$ respectively. Findings in the other aspects of cardiorespiratory examination were normal.

There were widespread maculopapular skin rashes with shiny exfoliating scaly surfaces involving the anterior abdominal wall, both legs and the extensor surfaces of both forearms (Figure 1). There were also islands of pustular rashes at the gluteal and sacral regions. There was a bulge measuring $8 \times 10 \mathrm{~cm}$ at its widest diameter over the anterior abdominal wall on the right hypochondrial region, with a transverse surgical scar and overlying skin rashes. The bulge was hard, non-tender, subcutaneous in location, with a surgical scar on the overlying skin. There were indurations along the subcutaneous region backwards to the region of L3/L4 vertebrate along the midline. 


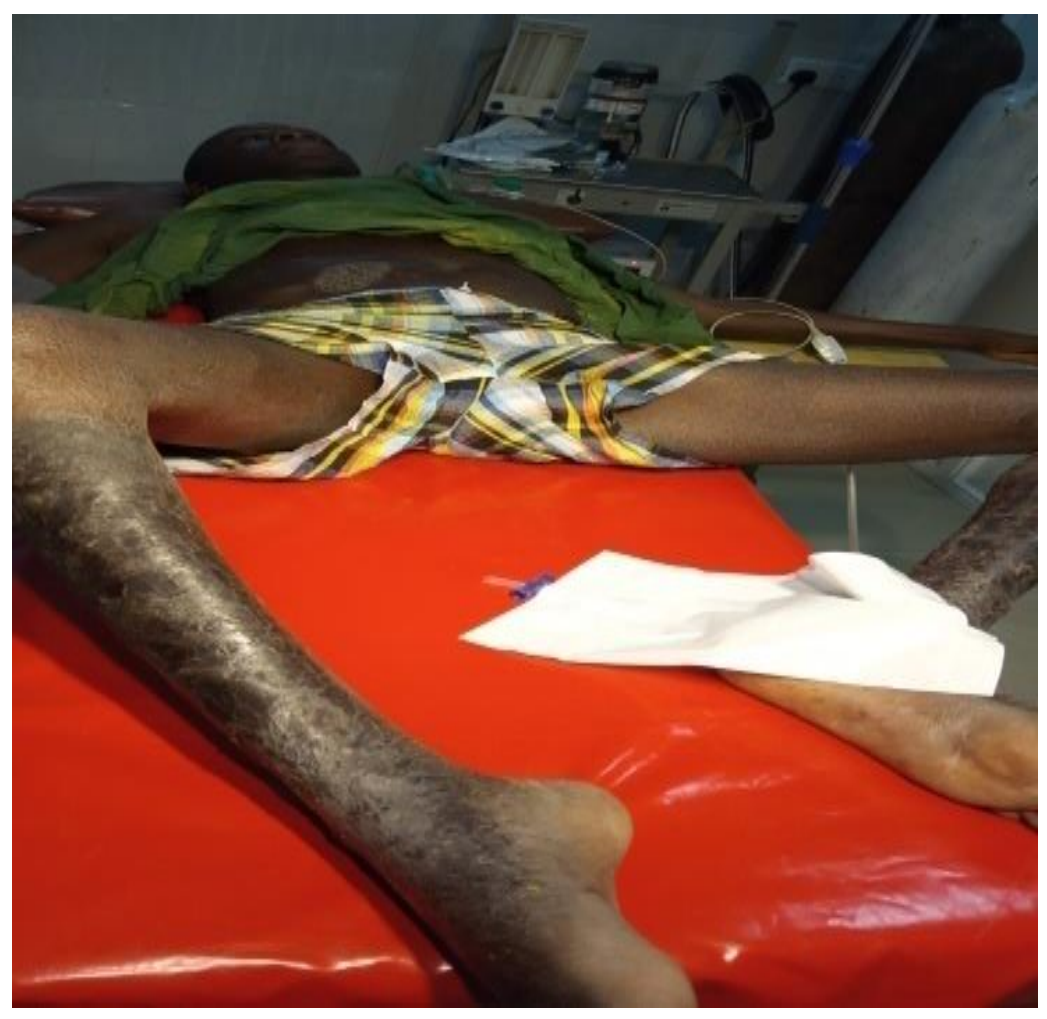

Figure 1: Maculopapular rashes on both legs

There was a midline surgical scar extending from the L3/L4 spinous posterior processes. The rest of the abdomen was normal. There was no back deformity. There was wasting of all groups of hand muscles and muscles of both lower limbs. The muscle bulk was also reduced in the lower limbs and the hands. The power in the dorsiflexors and plantar flexors group of muscles was $1 / 5$; it was $2 / 5$ for the knee flexors and knee extensors and $2 / 5$ for the hip flexors and extensors. The power on the muscles of the wrist was $3 / 5 ; 3 / 5$ for handgrip, while the power grade was normal for the elbow flexors and extensors and the shoulder groups of muscles.

There were patchy sensations in the lower and upper limbs. The superficial and deep tendon reflexes on the lower limbs were exaggerated. The biceps and triceps reflexes on the upper limbs were normal.
Plain abdominal X-Ray showed an opaque object around the right hypochondrial region (Figure 2). Magnetic Resonance Imaging of the cervical spine was not done because of the presence of a metallic implant, the nature of which was not precisely known.

The full blood count revealed White Blood Cell count of $9.5 \times 10^{3} / \mathrm{Ul}$, with differential counts of $42 \%, 36 \%, 7.2 \% 14.2 \%$ and $0.3 \%$ for lymphocytes, neutrophils, monocytes, eosinophils and basophils respectively. The haematocrit was 33\% and the platelet count was $350 \times 10^{9} / 1$. The serum electrolytes, urea, and creatinine parameters were within normal limits.

The dermatologist made a working diagnosis of allergic skin reaction to a foreign body to exclude acquired ichthyosis. Therefore, the patient was counselled for the explantation of the IBP. Surgical removal of the IBP was performed three 
days following the presentation. The findings at surgery included fibrous adhesions along the path of a transverse surgical scar. A subcutaneously placed Synchromed II,
Medtronic Pump with a tunnelled right flank subcutaneous catheter which ended at the epidural space between L3/L4 spine along the midline (Figures 3 and 4).

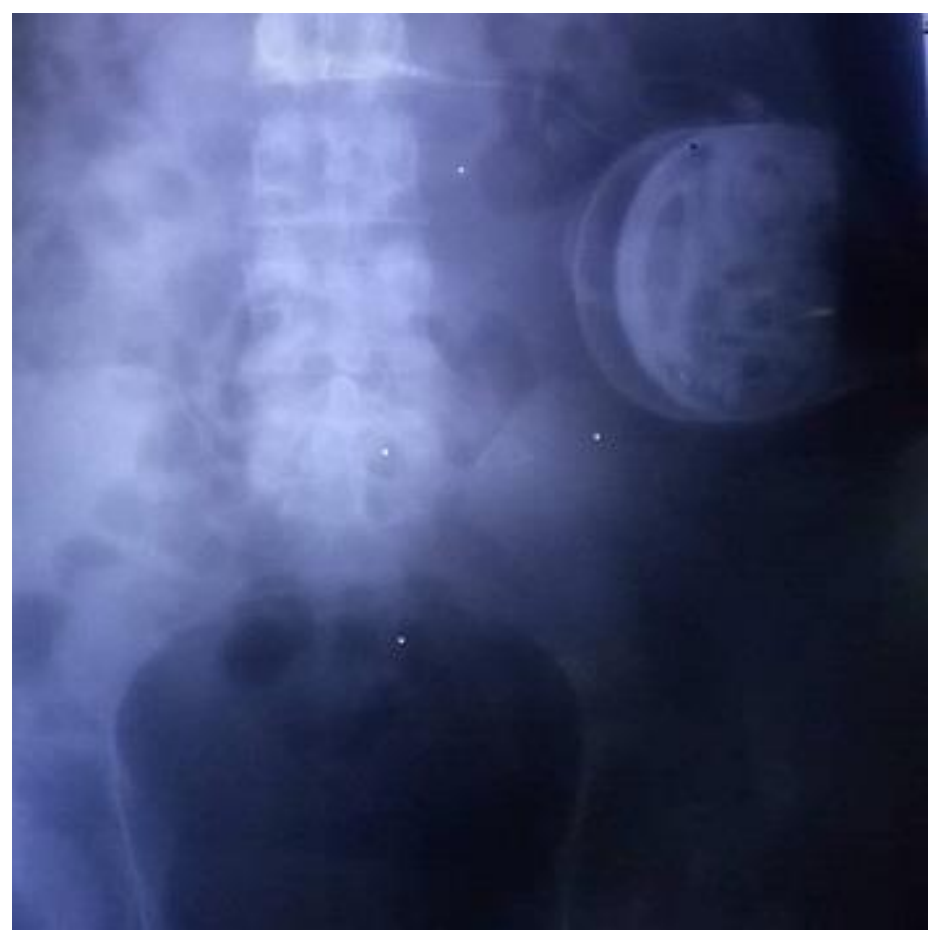

Figure 2: Plain abdominal X-Ray showing an opaque object around the right hypochondrial region

The patient improved clinically post-operatively and he was discharged on the seventh postoperative day on cefuroxime, chlorpheniramine and alpha hydroxyl acid ointment.

The patient was reviewed on a follow-up visit three months post-surgery. His abdominal and upper limb rashes had disappeared and that of the lower limb had reduced significantly (Figure 5). Though there was still residual spasticity, but the patient felt happy.

\section{Discussion}

The index case had IBP insertion for persistent and severe spasticity arising from an old posttraumatic cervical spine injury. He presented with generalized skin rashes which started three months following his second refill of Baclofen. Skin rashes are features of allergic skin reaction to a foreign body. [9-11] Dermatitis following baclofen pump insertion had been reported by Bernuz, et al. [9] The generalized distribution of the rashes was consistent with a foreign body skin reaction. [9,10,12] Though the patient was advised on six-monthly drug refill procedures, he was unable to meet up with the appointments due to financial constraints. This constrain is one of the drawbacks of medical tourism. [13] 


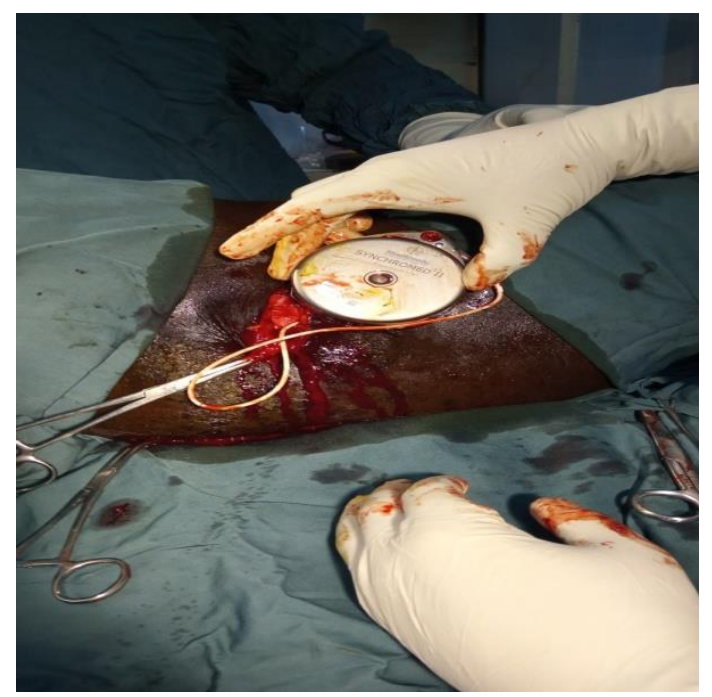

Figure 3: Intra-operative delivery of the baclofen pump via an anterior abdominal wall incision

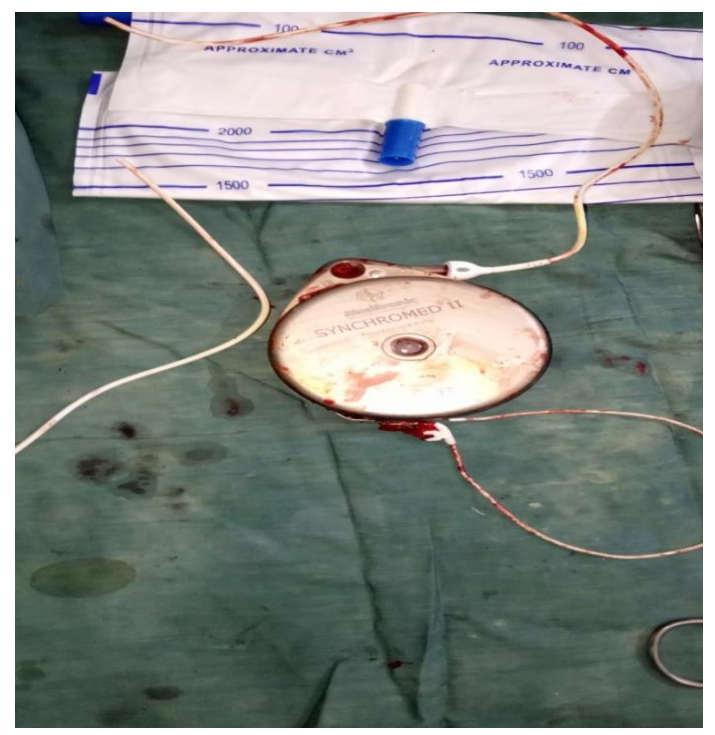

Figure 4: The Synchromed II, baclofen pump

The index case the IBP placed subcutaneously on the anterior abdominal wall. Subcutaneous insertion of IBP has been associated with higher complication rates compared to insertion in the sub-fascial pocket between the external oblique and the rectus abdominis. $[6,7,14]$ Tests of allergy based on the material content of the baclofen pump could not be carried out.
However, the diagnosis was based on the clinical picture and supported by the finding of eosinophilia, which is suggestive of allergy. Although baclofen pump is mainly made up of titanium alloy, no specific metallic element has been shown to provoke allergic skin reactions. This inference was further corroborated by the significant reduction in the skin lesions three months after the removal of the baclofen pump. 


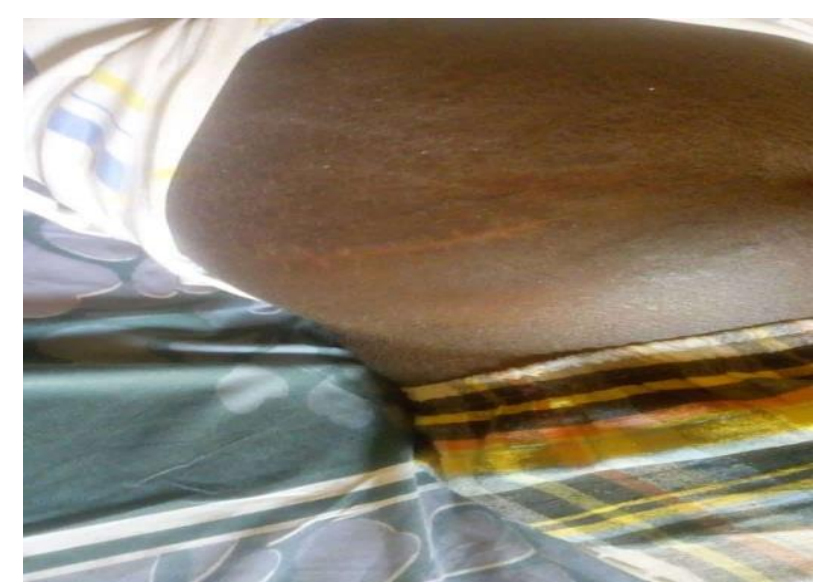

Figure 5: Healed post-operative skin incision

\section{Conclusion}

Allergic skin reactions to a foreign body are significant risks that may characterize the implantation of foreign material into the body. Most of these reactions cannot be predicted clinically. Therefore, it is pertinent for clinicians to identify these allergic reactions at the earliest time to minimize morbidity. Allergic skin reactions to a foreign body following baclofen pump implantation is rare and very few cases have been reported in the literature.

Authors' Contributions: AMK conceived the report and participated in data acquisition while MAA participated in literature review and manuscript drafting. Both authors approved the final version of the manuscript.

Conflict of Interest: None declared.

Funding: Self-funded.

Publication History: Submitted 19 June 2020; Accepted 25 September 2020.

\section{References}

1. Seth M. Woolf, Carl R. Baum. Baclofen Pumps Uses and Complications Pediatr Emerg Care
2017;

33:

271-275.

doi:10.1097/PEC.0000000000001090.

2. Hazelwood, MO. Gablofen. Baclofen injection. [Package Insert]. Mallinckrodt Brand Pharmaceuticals, Inc. 2015.

3. Penn RD, Koran JS. Intrathecal Baclofen alleviates spinal cord spasticity. Lancet. 1984; 1: 1078. doi:10.1016/s0140-6736(84)91487-9.

4. Krach LE. Pharmacotherapy of spasticity: oral medications and intrathecal baclofen. J Child Neurol 2001; 16: 31-36. doi:10.1177/088307380101600106.

5. Ghosh D, Mainali G, Khera J, Luciano M. Complications of Intrathecal Baclofen pumps in children: experience from a tertiary care center. Pediatr Neurosurg 2013; 49: 138-144. doi:10.1159/000358307.

6. Yasser A, Tamer R, Iram S, Norbert R, Kelly $\mathrm{M}$, Michael W. Complications of Intrathecal Baclofen Pump: Prevention and Cure. ISRN Neurol 2012; Article ID 575168. doi:10.5402/2012/575168.

7. Motta F, Buonaguro V, Stignani C. The use of Intrathecal Baclofen pump implants in children and adolescents: safety and complications in 200 consecutive cases. J 
Neurosurg (1 Suppl Pediatrics) 2007; 107: 32-

35. doi:10.3171/PED-07/07/032.

8. Paskhin DL, Dekopov AV, Tomsky AA, Isagulyan ED, Salova EM. Oslozhneniya intratekal'noi terapii baklofenom [Complications of intrathecal baclofen therapy]. Zh Vopr Neirokhir Im N N Burdenko 2017; 81: 63-69. doi:10.17116/neiro201780763-69.

9. Bernuz B, Assier H, Bisseriex H, Theibau I, Rech C, Schnitzler A. Intrathecal Baclofen Pump: A Foreign-Body Reaction Case Report and Its Solution. J Rehabil Med 2012; 44: 184185. doi:10.2340/16501977-0918.

10. Raque C, Goldschmidt H. Dermatitis associated with an implanted cardiac pacemaker. Arch Dermatol 1970; 102: 646649.

doi:10.1001/archderm.1970.04000120064011.
11. Buchet S, Blanc D, Humbert P, Giradin P, Vigan M, Anguenot T, Agache P. Pacemaker Dermatitis. Contact Dermatitis 1992; 26: 4647. doi:10.1111/j.1600-0536.1992.tb00867.x.

12. Moïni C, d'Alteroche A, Cosnay $P$, Vaillant $L$, Babuty D, Delhomme C, et al. Contact Dermatitis Following Cardiac Pacemaker Implantation. Arch Mal Coeur Vaiss 1996; 89: 253-256.

13. Abubakar M.K., Adamu K.M., Issues in Medical Tourism: A presentation of 3 Patients with Degenerative Spine Disease. Niger J Basic Clin Sci 2016; 13: 59-64. doi:10.4103/0331.8540.176043.

14. Borowski, Littleton AG, Borkhuu B, Presedo A, Shah S, Dabney KW, et al. Complications of Intrathecal Baclofen Pump Therapy in Pediatric Patients. J Pediatr Orthop 2010; 30: 76-81. doi:10.1097/BPO.0b013e3181c6b257. 